\title{
Definition of remission and relapse in polymyalgia rheumatica: data from a literature search compared with a Delphi-based expert consensus
}

\author{
Christian Dejaco, ${ }^{1}$ Christina Duftner, ${ }^{2,3}$ Marco A Cimmino, ${ }^{4}$ Bhaskar Dasgupta, ${ }^{5}$ \\ Carlo Salvarani, ${ }^{6}$ Cynthia S Crowson, ${ }^{7}$ Hilal Maradit-Kremers, ${ }^{7}$ Andrew Hutchings, ${ }^{8}$ \\ Eric L Matteson, ${ }^{7}$ Michael Schirmer, ${ }^{3}$ and members of the International Work Group for \\ PMR and GCA
}

\begin{abstract}
- Additional data are published online only. To view these files please visit the journal online at (http://ard.bmj.com).

${ }^{1}$ Department of Rheumatology, Medical University Graz, Graz, Austria

${ }^{2}$ Department of Internal Medicine, General Hospital of Kufstein, Kufstein, Austria

${ }^{3}$ Department of Internal Medicine I, Innsbruck Medical University, Innsbruck, Austria ${ }^{4}$ Department of Internal

Medicine, University of Genova, Genova, Italy

${ }^{5}$ Department of Rheumatology, Southend University Hospital,

Essex, UK

${ }^{6}$ Department of Rheumatology, Arcispedale S Maria Nuova,

Reggio Emilia, Italy

${ }^{7}$ Division of Rheumatology,

Mayo Clinic, Rochester,

Minnesota, USA

${ }^{8}$ Health Services Research Unit, London School of Hygiene and Tropical Medicine, London, UK
\end{abstract}

\section{Correspondence to}

Professor Michael Schirmer, Department of Internal

Medicine I, Innsbruck Medical University, Anichstrasse 35,

A-6020 Innsbruck, Austria; michael.schirmer@i-med.ac.at

Accepted 2 October 2010

Published Online First

19 November 2010

\section{ABSTRACT}

Objective To compare current definitions of remission and relapse in polymyalgia rheumatica (PMR) with items resulting from a Delphi-based expert consensus.

Methods Relevant studies including definitions of PMR remission and relapse were identified by literature search in PubMed. The questionnaire used for the Delphi survey included clinical $(n=33)$, laboratory $(n=54)$ and imaging $(n=7)$ parameters retrieved from a literature search. Each item was assessed for importance and availability/ practicability, and limits were considered for metric parameters. Consensus was defined by an agreement rate of $\geq 80 \%$.

Results Out of 6031 articles screened, definitions of PMR remission and relapse were available in 18 and 34 studies, respectively. Parameters used to define remission and/or relapse included history and clinical assessment of pain and synovitis, constitutional symptoms, morning stiffness (MS), physician's global assessment, headache, erythrocyte sedimentation rate (ESR), C-reactive protein (CRP), blood count, fibrinogen and/or corticosteroid therapy. In the Delphi exercise a consensus was obtained on the following parameters deemed essential for definitions of remission and relapse: patient's pain assessment, MS, ESR, CRP, shoulder and hip pain on clinical examination, limitation of upper limb elevation, and assessment of corticosteroid dose required to control symptoms.

Conclusions Assessment of patient's pain, MS, ESR, CRP, shoulder pain/limitation on clinical examination and corticosteroid dose are considered to be important in current available definitions of PMR remission and relapse and the present expert consensus. The high relevance of clinical assessment of hips was unique to this study and may improve specificity and sensitivity of definitions for remission and relapse in PMR.

\section{INTRODUCTION}

Polymyalgia rheumatica (PMR) is a common disease in older people conventionally treated with long-term oral corticosteroids. ${ }^{1-6}$

As corticosteroid treatment leads to rapid improvement in symptoms and returns patients to pre-morbid functional status, interventional studies in PMR usually focus on parameters such as 'complete remission' or 'time in remission to relapse', rather than on partial response criteria used in other immune-mediated diseases. ${ }^{7-10}$ However, there is still considerable uncertainty related to definitions of 'remission' and 'relapse' in PMR, with disparate use of criteria used to define these disease states in PMR treatment studies to date.

New definitions of remission and relapse have been proposed by Leeb et al ${ }^{11}$ and Binard et al, ${ }^{12}$ respectively. Both definitions were based on the PMR activity score (PMR-AS), which was developed using predefined parameters and was not subject to a consensus finding process including a systematic literature review. ${ }^{13}{ }^{14}$ The validity of the PMR-AS has been supported in a number of studies. ${ }^{11} 121516$

This paper presents the results from a Delphibased consensus survey involving rheumatologists (RMs) and general practitioners (GPs) identifying candidate items for new definitions of remission and relapse. We compared these parameters with currently available remission and relapse definitions retrieved from a systematic literature review.

\section{METHODS}

\section{Literature search}

A literature search was conducted in PubMed, Medline (from January 1966 to November 2003, updated June 2009), using the items 'Polymyalgia rheumatica', 'PMR', 'Giant cell arteritis', 'Polymyalgia rheumatica AND Remission' and 'Polymyalgia rheumatica AND Relapse' as keywords. Only studies written in English were included. All studies were screened for definitions of remission and/or relapse of PMR and parameters used to define these conditions in PMR.

\section{Delphi exercise}

We used a two-step Delphi process. Firstly, we generated a questionnaire with candidate items for definitions of remission and relapse of PMR as retrieved in a literature search. The final questionnaire included 94 items categorised into 'history' ( $\mathrm{n}=19)$, 'physical examination' ( $\mathrm{n}=14)$, 'laboratory findings' ( $n=54)$ and 'imaging methods' $(n=7)$. One questionnaire each was used to assess the definition of remission on treatment medication (reflecting short-term response to corticosteroids), remission off medication (longer-term outcome after withdrawal of corticosteroids) and relapse (when the patient is still taking corticosteroids). Availability and practicability of all criteria were separately assessed. In the first round, experts indicated the 
importance ('essential', 'less important' or 'not important') and availability/practicability ('routinely available/practicable', 'not always available/difficult to perform' or 'not available/practicable') of diagnostic tools. Availability of diagnostic tools was examined in this round only. Experts were encouraged to add further candidate criteria to be considered for assessment and relevant comments. In addition, experts were asked to suggest cut-off points for the proposed quantitative candidate criteria items based on data from the literature review. Questionnaires were distributed to all experts via mail or e-mail. Experts were contacted by telephone and/or reminders were sent to encourage participation and return of questionnaires.

The questionnaire used in the second round was derived from that of the first round using results from the first round. Parameters considered 'not available' or 'not important' by $\geq 50 \%$ or 'essential' by $<20 \%$ of experts were excluded. Items regarded as essential by $\geq 80 \%$ of experts for the definition of remission and/or relapse were accepted as consensus items and not further assessed. First-round results of the remaining parameters were illustrated to the experts by pie diagrams. Then, experts were asked to re-evaluate the parameters either as 'important' or 'not important' to the definition of remission and/or relapse of PMR. In addition, experts were encouraged to choose a limit for quantitative items among those proposed in the first round. All written comments were attached anonymously.

As first-round analysis of questionnaires for remission 'on medication' and 'off medication' showed almost perfect agreement, no separate assessment for remission 'on medication' and 'off medication' was performed in the second round. Only the parameter 'patient's assessment of pain related to neck, upper arms, shoulders and pelvic girdle by a visual analogue scale (VAS)' revealing some disagreement was reassessed.

\section{Experts}

We invited 25 RMs from Europe (Italy $(n=6)$, Sweden ( $n=1)$, UK $(n=2)$, France $(n=1)$, Austria $(n=3)$, Spain $(n=2)$, Germany $(n=3))$, Israel $(n=1)$ and the USA $(n=6)$ experienced in treatment and research of PMR to participate. Most of them are members of the International Work Group for PMR and GCA. ${ }^{17} \mathrm{RMs}$ were asked to propose one GP experienced in treating patients with PMR and willing to participate in the study.

\section{Statistical analysis}

Statistical analyses were performed using SPSS, V.11.0. Responses were analysed by descriptive statistics as appropriate. Invalid or missing data were excluded.

\section{RESULTS}

\section{Literature research}

Of 6031 articles screened, 1851 were excluded because they were written in a language other than English, and 2500 reports were editorials, comments, or letters without original data. Of the 1680 remaining papers, we identified 18 and 34 that contained definitions of PMR remission and relapse, respectively: one paper each with a definition of PMR remission and relapse based on PMR-AS (table 1) and an additional 17 and 33 papers containing remission and relapse criteria not based on PMR-AS, respectively (tables 2 and 3 ).

\section{Delphi exercise}

Responses by invited physicians to the first round of questionnaires were 34/50 (25 RMs (100\%) and nine GPs (36\%)) and to the second round 22/34 (19 RMs (76\%) and three GPs (12\%)).
Owing to the low response rate from GPs, we restricted our final analyses of both questionnaire rounds to results derived from RMs. The omission of data from GPs did not significantly alter the results of the Delphi exercise. Pooled data for RMs and GPs are shown in online supplementary tables $1 b, 2 b, 3 b$ and 4.

Results of the first questionnaire round

After the first questionnaire round, 64 out of 94 parameters were considered 'not important' for the definition of remission, and 65/94 were considered 'not important' for defining relapse by the majority of RMs. The 64 parameters for remission included $6 / 19$ from the category history, 2/14 from physical examination, $50 / 54$ from laboratory findings, and 6/7 from imaging methods. The 65 parameters considered not important for defining relapse included 7/19 from history, 2/14 from physical examination, 50/54 from laboratory findings, and 6/7 from imaging methods.

Questionnaires related to remission 'on medication' and 'off medication' showed very high agreement ( $\kappa$ 0.93). Data from both questionnaires led to exclusion or consensus on the same parameters except for the parameter 'patient's assessment of pain related to neck, upper arms, shoulders and pelvic girdle by a VAS', which was considered to be essential by $81.8 \%$ of RMs for 'remission on medication' (=consensus), and by $79.2 \%$ for 'remission off medication'.

Availability of items for definitions of remission and relapse Of 94 parameters from the literature, 29 were considered as routinely available/practicable by more than $80 \%$ of RMs (10/19 parameters out of the category history, 12/14 out of clinical examination, 7/54 out of laboratory findings, and $0 / 7$ out of imaging methods) (see online supplementary tables $1 \mathrm{a}$ and $2 \mathrm{a}$ for detailed results).

Eight parameters (all blood tests for cytokines or cytokine receptors) were considered to be not available.

\section{Results of the second questionnaire round}

Tables 4 (remission) and 5 (relapse) depict those items for which RMs achieved a consensus following the two Delphi rounds. The limits for metric parameters were proposed in the first questionnaire round and rated in the second round.

Assessment of symmetric synovitis with peripheral oedema as seen in $\mathrm{RS}_{3} \mathrm{PE}$ (remitting seronegative syndrome with pitting oedema), peripheral arthritis, patient's and physician's global assessment, history of transient visual symptoms, fever and physician's pain assessment were important for $>50 \%$ of RMs in defining remission and relapse in both questionnaire rounds but did not reach consensus level (see online supplementary table $3 \mathrm{a}$ for detailed results).

\section{Comparison of parameters resulting from Delphi exercise with previous definitions of remission and relapse of PMR}

Previous definitions of remission and relapse not based on PMR-AS included the parameters patient's assessment of pain

Table 1 Definitions of remission and relapse based on the polymyalgia rheumatica activity score (PMR-AS) by Leeb and Bird ${ }^{14}$

\begin{tabular}{|c|c|}
\hline \multicolumn{2}{|c|}{$\begin{array}{l}\text { PMR-AS }=\text { CRP }(\mathrm{mg} / \mathrm{dl})+\text { patient's pain assessment }(\text { VAS } 0-10)^{*}+\text { physician's } \\
\text { global assessment }(\text { VAS } 0-10) \dagger+(\text { morning stiffness }(\mathrm{min}) \times 0.1)+\text { EUL }(0-3) \ddagger\end{array}$} \\
\hline Remission 11 & $0-1.5$ \\
\hline Relapse $^{12}$ & $>9.35$ or a $\Delta$ PMR-AS score $>6.6$ \\
\hline
\end{tabular}


Table 2 Definitions of remission of polymyalgia rheumatica from the published literature

\begin{tabular}{|c|c|c|c|c|c|c|c|c|}
\hline \multirow[b]{2}{*}{ Reference } & \multirow[b]{2}{*}{ History } & \multirow[b]{2}{*}{ Clinical examination } & \multicolumn{5}{|l|}{ Laboratory } & \multirow[b]{2}{*}{ Therapy } \\
\hline & & & $\begin{array}{l}\text { ESR } \\
\text { (mm/1st h) }\end{array}$ & CRP (m & $\mathrm{lg} / \mathrm{dl})$ & Blood count & $\begin{array}{l}\text { Fibrinogen } \\
\text { ( } \mu \mathrm{mol} / \mathrm{l})\end{array}$ & \\
\hline Behn et a/30 & ACS & & $<30$ & - & & - & - & - \\
\hline Cantini et al/27 & ACS & & $<40$ & $<0.5^{*}$ & & - & - & - \\
\hline Catanoso et a $/^{9}$ & $\begin{array}{l}\text { Absence of systemic symptoms } \\
\text { (fever, malaise, anorexia, weight } \\
\text { loss), MS, girdles and neck pain } \\
\text { and peripheral synovitis }\end{array}$ & - & $<40$ & $<0.5^{*}$ & - & & - & - \\
\hline Chuang et $a /^{41}$ & ACS & & \multicolumn{3}{|c|}{ Normal laboratory findings } & & & - \\
\hline Dasgupta et a/42 & $\begin{array}{l}\geq 50 \% \text { pain reduction (VAS) MS } \\
<30 \text { min }\end{array}$ & - & $<20$ & - & & $\mathrm{Hb}>12 \mathrm{~g} / \mathrm{dl}$ & - & - \\
\hline Delecoeuillerie et a/43 & ACS & & - & - & & - & - & - \\
\hline Feinberg et al ${ }^{44}$ & & $\begin{array}{l}\text { Absence of pain on } \\
\text { examination }\end{array}$ & NV & - & & - & - & - \\
\hline Ferraccioli et a/45 & Absence of myalgias & - & NV & NV & & - & - & - \\
\hline Hutchings et $a /^{46}$ & $\begin{array}{l}\geq 50 \% \text { improvement in shoulder } \\
\text { and pelvic girdle pain on a VAS, } \\
\mathrm{MS} \leq 30 \text { min }\end{array}$ & - & $\leq 30$ & $\leq 1.0$ & - & & - & - \\
\hline Kremers et $a^{31} 3435$ & ACS & & NV & - & - & & - & $\mathrm{CS} \leq 5 \mathrm{mg} /$ day \\
\hline Krogsgaard et a/ ${ }^{47}$ & No muscular pain, no MS & No muscular tenderness & NV & - & & - & NV & Lowest CS possible \\
\hline Martinez-Taboada et al ${ }^{48}$ & ACS & & NV & - & & - & - & - \\
\hline Mertens et al ${ }^{49}$ & ACS & & - & - & & - & - & - \\
\hline Proven et $a{ }^{36}$ & ACS & & & & & & & \\
\hline Salvarani et $a l^{26}$ & ACS & & $\leq 30$ & $\leq 0.5^{*}$ & - & & - & - \\
\hline Salvarani et a/ ${ }^{8}$ & ACS & & NV & - & - & & - & - \\
\hline Van der Veen et $a /^{50}$ & & & & & & & & $\begin{array}{l}\text { Discontinuation of prednisone } \\
\text { and trial medication }\end{array}$ \\
\hline
\end{tabular}

\footnotetext{
"The upper limit of normal is $0.5 \mathrm{mg} / \mathrm{dl}$; for the other studies, no upper limit of normal CRP levels was reported.

- , parameter not mentioned in the definition.

ACS, absence of clinical symptoms (not further specified); CRP, C-reactive protein; CS, corticosteroid dose; ESR, erythrocyte sedimentation rate; Hb, haemoglobin; MS, morning stiffness; NV, normal values; VAS, measured on a visual analogue scale ranging from 0 (best) to 10 (worst) $\mathrm{cm}$.
}

(29.4\% and $21.2 \%$, respectively), MS $(23.5 \%$ and $21.2 \%$, respectively), ESR (70.6\% and $60.6 \%$, respectively), CRP $(29.4 \%$ and $30.3 \%$, respectively) and shoulder pain/limitation on clinical examination (11.8\% and $0 \%$, respectively); and these parameters also reached consensus level in the Delphi exercise and are included in the PMR-AS (ESR may be used instead of CRP according to the original work by Leeb et al $\left.{ }^{13}{ }^{14}\right)$. Physician's global assessment is part of the PMR-AS, but did not achieve consensus level in the Delphi study with $57.9 \%$ and $56.2 \%$ agreement for remission and relapse, respectively. Assessment of corticosteroid dose (remission)/response to corticosteroids (relapse) and hip symptoms judged to be important by $>80 \%$ of experts in the Delphi survey are not part of the PMR-AS and were specifically included in $17.6 \%$ and $11.8 \%$ of previous definitions of remission, respectively, and $60.6 \%$ and $12.1 \%$ of previous definitions of relapse, respectively, not based on PMR-AS. Peripheral synovitis, patient's global assessment, history of transient visual symptoms, history of fever, and physician's pain assessment were all important for the majority of RMs in the Delphi exercise, but are considered by $<6 \%$ of previous remission and relapse definitions including the PMR-AS.

\section{DISCUSSION}

This international Delphi survey among RM experts corroborated some previously proposed items for the definition of PMR remission and relapse including patient's assessment of pain, MS, ESR, CRP, shoulder pain/limitation on clinical examination, and corticosteroid dose required to control symptoms. Many other items, such as determination of haemoglobin and fibrinogen, were considered to have little value for this purpose.

The consensus on hip involvement was unexpected, as this parameter was only considered in $2 / 17$ and $4 / 33$ previous studies with definitions of remission and relapse, respectively, and was not included in the PMR-AS. In addition, we observed a high relevance ( $>50 \%$ agreement) of peripheral manifestations and fever compared with previous literature. Hips are involved in $50-70 \%$ of patients with PMR, and peripheral or constitutional symptoms occur in $30-50 \% .{ }^{18}$ Assessment of these clinical features with incorporation into definitions of remission and relapse may lead to higher specificity and sensitivity of these definitions and possibly allow improved classification of those $10-30 \%$ of patients who lack shoulder symptoms. ${ }^{18}$

Clear improvement in, or flare of, PMR using clinical symptoms such as pain or MS was considered to be important by experts in the present survey. These parameters are included in the PMR-AS, and most proposed remission and/or relapse definitions in the current literature. However, this international PMR/GCA study group recently questioned the value of MS, as patients and clinicians may not reliably distinguish between pain and stiffness. ${ }^{17} \mathrm{~A}$ major concern is that pain-related items may lack specificity given the high prevalence of osteoarthritis and degenerative pain in older people. ${ }^{19}$ The occurrence of unilateral versus bilateral pain may be useful in this regard; however, a prospective study is needed to clarify the true value of pain and stiffness in defining remission and relapse in PMR.

The biometric limits for clinical items (eg, duration of MS) chosen by experts in the present survey were comparable to those available from a literature search and the PMR-AS. In the present Delphi survey and previous definitions of remission and relapse, cut-off values were preferred to relative changes in the parameters during follow-up. A relevant consideration in this regard is that all such measures should be zero for a PMR patient in remission. However, many older patients with arthritic/rheumatic conditions rarely consider themselves to be completely free from pain and stiffness. ${ }^{20}$ Therefore, several 
Table 3 Definitions for relapse of polymyalgia rheumatica from the published literature

\begin{tabular}{|c|c|c|c|c|}
\hline Reference & Elevation of ESR* (mm/1st h) & Elevation of CRP (mg/dl) & Flare of PMR clinical features* & Response to corticosteroids* \\
\hline Amoli et al ${ }^{51}$ & - & - & Yes & Yes \\
\hline Ayoub et $a^{\beta 8}$ & - & - & Yes & Yes \\
\hline Bahlas et $a^{33}$ & - & - & Yes & Yes \\
\hline Behn et a/30 & NN & - & Yes & - \\
\hline Blockmans et al ${ }^{21}$ & $>40$ (NN) & $>3.0(\mathrm{NN})^{\dagger}$ & MS, proximal girdle pain & - \\
\hline Cantini et a/27 & $>30$ (NN) & - & Yes & Yes \\
\hline Catanoso et a ${ }^{9}$ & $\geq 40 \ddagger$ & $\geq 0.5 \dagger$ & $\begin{array}{l}\text { Typical proximal musculoskeletal } \\
\text { symptoms, MS } \geq 1 \mathrm{~h}\end{array}$ & - \\
\hline Ceccato et a/52 & NN & - & Yes & Yes \\
\hline Chuang et a/41 & NN & - & Yes & Yes \\
\hline Cimmino et $a^{5354}$ & $>30^{\ddagger}$ & $>0.5$ & $\begin{array}{l}\text { Aching and stiffness at shoulder } \\
\text { and/or hip girdle }\end{array}$ & - \\
\hline Cutolo et $a / 55$ & $>30$ (NN) & - & Yes & - \\
\hline González-Gay et a/ ${ }^{56}$ & - & - & Yes & Yes \\
\hline Hachulla et al22 & $>30^{\ddagger}$ & $>1.2 \pi$ & $\begin{array}{l}\text { Fever, proximal aching and MS, myalgia, } \\
\text { weakness, weight loss, headache (NN)§ }\end{array}$ & Yes (or to dapsone) \\
\hline Hutchings et al/6 & - & - & Yes & $\begin{array}{l}\text { Yes or maintenance of the steroid } \\
\text { dose beyond a scheduled reduction }\end{array}$ \\
\hline Kremers et $a^{\beta 1}$ & - & - & Yes & $\begin{array}{l}\text { Yes (and requiring a dose increment } \\
\geq 5 \mathrm{mg} / \mathrm{day} \text { ) }\end{array}$ \\
\hline Kremers et a $a^{34}$ & - & - & Yes & Yes \\
\hline Kyle and Hazleman ${ }^{57}$ & - & - & $\begin{array}{l}\text { Pain and stiffness in the shoulder or } \\
\text { hip girdle }\end{array}$ & - \\
\hline Lundberg and Hedfors ${ }^{58}$ & - & - & Yes & Yes \\
\hline Mertens et $a /^{49}$ & - & - & Yes & Yes \\
\hline Narváez et a/23 & Yes & - & Yes & Yes \\
\hline von Knorring ${ }^{29}$ & NN & - & Yes & Yes \\
\hline
\end{tabular}

- , parameter not mentioned in the definition.

* Not further specified unless otherwise stated.

FIncremental change in either ESR or CRP for the definition of relapse.

$\S$ No other intercurrent inflammatory syndrome.

CRP, C-reactive protein; the upper limit of normal is ${ }^{\dagger} 0.5 \mathrm{mg} / \mathrm{dl}$ and $\uparrow 1.2 \mathrm{mg} / \mathrm{dl}$ (for the other studies, no upper limit of normal CRP levels was reported); ESR, erythrocyte sedimentation rate; MS, morning stiffness; NN, not necessarily.

PMR studies define remission pragmatically as absence of relapse or as duration of relapse-free survival, accepting higher (non-zero) biometric limits for patients in remission. ${ }^{21-25}$ This strategy for defining remission has the advantage of a high sensitivity, classifying all patients with PMR as either in remission or relapse. In contrast, developing separate remission and relapse criteria results in a high specificity of classification, but suggests an additional (yet undefined) disease state that is neither remission nor relapse. Sensitivity and specificity of such definitions may differ, if relevant parameters are used as a qualitative set of criteria or a composite score, such as the PMR-AS. In rheumatoid arthritis and other rheumatic diseases, composite scores are usually preferred, whereas most treatment studies in PMR to date have used qualitative sets of criteria. The question of which approach is more useful for daily clinical practice and outcome studies remains to be addressed by future studies.
In this Delphi exercise, both ESR and CRP were assumed to be routinely available and to be the most promising laboratory items for defining both remission and relapse. While CRP is a component of the PMR-AS, other published studies have preferentially used a normal ESR as a component of their remission definition. Persistently raised CRP has been suggested to correlate better with inflammation in PMR than ESR and may thus be better suited for use in definitions of remission and relapse. ${ }^{26}$ An important limitation of CRP and ESR is that these may be normal (not increased) in up to $20 \%$ of patients with PMR at the time of diagnosis. ${ }^{18}$ Indeed, normal ESR or CRP values have been observed in up to $27 \%$ and $14 \%$ of relapses, respectively, despite the increase in these parameters at the time of diagnosis. ${ }^{10}$ 27-29 Thus a flare of PMR symptoms may occur in the absence of abnormal inflammatory parameters, although degenerative pain with stiffness may also mimic a flare of the disease. 
Table 4 Parameters considered as 'important' for defining remission of polymyalgia rheumatica by at least $80 \%$ of rheumatologists (RMs)

\begin{tabular}{|c|c|c|}
\hline Parameter & Limits & Agreement (\%) \\
\hline Morning stiffness $^{*}$ & $\begin{array}{l}<15 \min \\
<30 \min \end{array}$ & $\begin{array}{r}94.7 \\
5.3\end{array}$ \\
\hline Erythrocyte sedimentation rate ${ }^{*}$ & $\begin{array}{l}<20 \mathrm{~mm} / 1 \mathrm{st} \mathrm{h} \\
<30 \mathrm{~mm} / 1 \mathrm{st} \mathrm{h} \\
<40 \mathrm{~mm} / 1 \mathrm{st} \mathrm{h}\end{array}$ & $\begin{array}{l}57.9 \\
31.6 \\
10.5\end{array}$ \\
\hline C-reactive protein ${ }^{*}, \dagger$ & $\begin{array}{l}<0.5 \mathrm{mg} / \mathrm{dl} \\
<0.8 \mathrm{mg} / \mathrm{dl} \\
<1.0 \mathrm{mg} / \mathrm{dl}\end{array}$ & $\begin{array}{l}68.4 \\
10.5 \\
21.2\end{array}$ \\
\hline $\begin{array}{l}\text { Patient's assessment of pain related to neck, upper arms, } \\
\text { shoulders and pelvic girdle (VAS) }\end{array}$ & $\begin{array}{l}<10 \mathrm{~mm} \\
<20 \mathrm{~mm} \\
<25 \mathrm{~mm}\end{array}$ & $\begin{array}{r}58.8 \\
35.3 \\
5.9\end{array}$ \\
\hline Corticosteroid dose required to control symptoms ${ }^{*}$ & Limit not specified $\ddagger$ & \\
\hline Shoulder-pain worsened by passive and active mobilisation & Qualitative item & \\
\hline Limitation of upper limb elevation & Qualitative item & \\
\hline Clinical signs of coxofemoral synovitis ${ }^{\S}$ & Qualitative item & \\
\hline
\end{tabular}

The corresponding proposals for limits of metric parameters and the agreement to these limits are given.

*Consensus on this parameter was already obtained in the first Delphi round.

tUpper limit of a normal C-reactive protein value is $0.5 \mathrm{mg} / \mathrm{dl}$.

${ }^{\ddagger} \mathrm{A}$ certain corticosteroid dose limit for remission on treatment medication (ie, when a patient is still on corticosteroids) was not

specified by RMs in the Delphi survey. Corticosteroid dose of zero defines the case of remission off medication (ie, when the patient stopped taking corticosteroids).

${ }^{\S}$ Coxofemoral synovitis is suggested if the patient complains about pain in the groin worsened by passive and active movements on clinical examination.

VAS, visual analogue scale with $0=$ no pain, $10=$ unbearable pain on a $10 \mathrm{~cm}$ scale.

Table 5 Parameters considered as 'important' to define relapse of polymyalgia rheumatica by at least $80 \%$ of rheumatologists (RMs)

\begin{tabular}{|c|c|c|}
\hline Parameter & Limits & Agreement (\%) \\
\hline Morning stiffness* & $\begin{array}{l}>30 \min \\
+20 \%\end{array}$ & $\begin{array}{r}94.7 \\
5.3\end{array}$ \\
\hline Erythrocyte sedimentation rate ${ }^{*}$ & $\begin{array}{l}>40 \mathrm{~mm} / 1 \mathrm{st} \mathrm{h} \\
>20 \mathrm{~mm} / 1 \mathrm{st} \mathrm{h} \\
\geq 2 \times \text { previous }\end{array}$ & $\begin{array}{r}57.9 \\
36.8 \\
5.3\end{array}$ \\
\hline C-reactive protein ${ }^{*},+$ & $\begin{array}{l}>1.0 \mathrm{mg} / \mathrm{dl} \\
>0.5 \mathrm{mg} / \mathrm{dl} \\
>2.0 \mathrm{mg} / \mathrm{dl} \\
\geq 2 \times \text { previous }\end{array}$ & $\begin{array}{l}52.6 \\
21.1 \\
15.9 \\
10.5\end{array}$ \\
\hline $\begin{array}{l}\text { Patient's assessment of pain related to neck, upper arms, shoulders and } \\
\text { pelvic girdle (VAS) }\end{array}$ & $\begin{array}{l}>20 \mathrm{~mm} \\
>50 \mathrm{~mm}\end{array}$ & $\begin{array}{r}93.8 \\
6.2\end{array}$ \\
\hline Corticosteroid dose required to control symptoms ${ }^{*}$ & $\begin{array}{l}\text { Any dose } \uparrow \\
+2.5 \mathrm{mg} / \text { day } \\
\geq 10 \mathrm{mg} / \text { day }\end{array}$ & $\begin{array}{r}62.4 \\
31.2 \\
6.2\end{array}$ \\
\hline Shoulder pain worsened by passive and active mobilisation & Qualitative item & \\
\hline Limitation of upper limb elevation & Qualitative item & \\
\hline Clinical sign of coxofemoral synovitis ${ }^{\ddagger}$ & Qualitative item & \\
\hline
\end{tabular}

The corresponding proposals for a limit of metric parameters and the agreement rate to these limits are given.

${ }^{*}$ Consensus on this parameter was already obtained in the first Delphi round.

tUpper limit of a normal C-reactive protein value is $0.5 \mathrm{mg} / \mathrm{dl}$.

$\ddagger$ Coxofemoral synovitis is suggested if the patient complains about pain in the groin worsened by passive and active movements on clinical examination.

VAS, visual analogue scale with $0=$ no pain, $10=$ unbearable pain on a $10 \mathrm{~cm}$ scale.

A relapse of PMR can be defined even with normal CRP and/ or ESR using the PMR-AS and definitions from 22 of the 33 other studies from the literature search. Notably, the PMR-EULAR response criteria that provide the basis for the PMR-AS were developed in a cohort of PMR patients who all had raised ESR and CRP values at the time of diagnosis. ${ }^{13}$ In the present survey, the possibility of relapse in the absence of abnormally increased ESR and/or CRP was not addressed and requires future clarification.

The other laboratory parameters evaluated, including blood count, markers of vascular damage/activation, hormones and cytokines/receptors, were considered less important in evaluating relapse and remission at this point in time.

Corticosteroids are the mainstay of treatment for PMR, although the optimal initial dose and tapering regimen are matters of ongoing debate. ${ }^{130-32}$ Assessment of corticosteroid dose may be important to the definition of remission. A related consideration is that physicians and patients may be unwilling to accept the status of 'remission' if achieved at the expense of serious impairment of the patient's general well-being due to side effects of unacceptably high corticosteroid doses. ${ }^{11}$ Maintaining a treatment-free complete clinical response after stopping treatment remains the clinical goal, which is not always achievable in PMR. ${ }^{11} 33$

In the present survey, $>80 \%$ of experts were of the opinion that corticosteroid doses should be included in any definition of remission in PMR. While agreeing that the corticosteroid dose 'should be as low as possible', a specified dose limit was not agreed upon. A prospective study would be needed to clarify whether the assessment of corticosteroid doses improves the specificity of a definition of remission. 
The majority of experts thought that the need for any increment in corticosteroid dose necessary to control PMR symptoms should be included in the criteria for defining relapse. This result is in accordance with 20 studies from our literature search, which considered a flare of PMR symptoms to be a relapse if symptoms respond to an increased dose of corticosteroid.

To address possible differences related to useful parameters for assessing short-term (ie, remission when the patient is taking corticosteroids) and long-term (ie, remission after treatment withdrawal) outcomes in PMR, we used different questionnaires to define remission 'on medication' and 'off medication'. The ratings of the two questionnaires showed almost perfect agreement, indicating that the same clinical parameters may be useful for defining both states of remission. However, we did not address the role of time with respect to remission, as has been reported previously. ${ }^{30} 31$ 34-37 The time in remission after withdrawal of treatment is of particular interest in distinguishing patients in 'permanent' remission or at low risk of relapse from those at high risk of relapse. ${ }^{28} 38$ This issue remains to be clarified.

We invited 50 experts to participate in this Delphi exercise, recognising that no optimal number of experts for such a study exists. The reliability of results may decline rapidly with fewer than six panel members, whereas improvements in reliability are relatively small in groups larger than $15 .{ }^{39} 40$ There is also no definition of an 'expert' status for a Delphi study, but, as PMR is diagnosed by RMs and GPs, we sought to consider opinions of both groups of physicians. A survey among French GPs revealed that only $36 \%$ of GPs routinely refer PMR patients to a RM for diagnosis of the disease and that only $20 \%$ of these GPs take advice from RMs for routine follow-up of PMR patients. ${ }^{15}$ Therefore we asked participating RMs to recommend one GP each in order to involve an international group of GPs with adequate experience in rheumatology. Only nine and three GPs responded to the first and second questionnaire rounds, respectively, despite recurrent telephone contacts and/or written reminders. The low response rate for GPs limits the validity of their responses, and therefore we restricted our final analysis to data derived from RMs. The omission of data from GPs, however, did not significantly alter the results.

The two rounds of questionnaires resulted in a quite limited number of parameters being accepted by the majority of experts. Many others did not achieve the predefined level of consensus. It is possible that another round addressing at least some of these items further may have resulted in them being classified as consensus items or as not important. Further rounds of questionnaires were not pursued, in part because of concern that respondent fatigue might seriously erode the value of the exercise.

The items that emerged from this Delphi-based expert consensus as important for defining relapse and remission in patients with PMR were patient's assessment of pain related to neck, upper arms, shoulders and pelvic girdle, MS, ESR, CRP, shoulder pain/limitation on clinical examination, and corticosteroid dose. Clinical assessment of the hips turned out to be important in this survey and may further improve specificity and sensitivity of defining remission and relapse in PMR. The operating characteristics and value of the remission and relapse items derived in this exercise will require prospective evaluation.

\section{Competing interests None.}

Provenance and peer review Not commissioned; externally peer reviewed.

\section{REFERENCES}

1. Lawrence RC, Felson DT, Helmick CG, et al. Estimates of the prevalence of arthritis and other rheumatic conditions in the United States. Part II. Arthritis Rheum 2008; $58: 26-35$

2. Duftner C, Dejaco C, Schirmer M. [Polymyalgia rheumatica]. Internist (Berl) 2009;50:51-7; quiz 58-9.

3. Walsh LJ, Wong CA, Pringle M, et al. Use of oral corticosteroids in the community and the prevention of secondary osteoporosis: a cross sectional study. BMJ 1996;313:344-6.

4. Gabriel SE, Sunku J, Salvarani C, et al. Adverse outcomes of antiinflammatory therapy among patients with polymyalgia rheumatica. Arthritis Rheum 1997; 40:1873-8

5. Dasgupta B, Borg FA, Hassan N, et al. BSR and BHPR guidelines for the management of polymyalgia rheumatica. Rheumatology (Oxford) 2010;49:186-90.

6. Dasgupta B, Matteson EL, Maradit-Kremers H. Management guidelines and outcome measures in polymyalgia rheumatica (PMR). Clin Exp Rheumatol 2007;25(6 Suppl 47):130-6.

7. Weyand CM, Fulbright JW, Evans JM, et al. Corticosteroid requirements in polymyalgia rheumatica. Arch Intern Med 1999;159:577-84.

8. Salvarani C, Macchioni P, Manzini C, et al. Infliximab plus prednisone or placebo plus prednisone for the initial treatment of polymyalgia rheumatica: a randomized trial. Ann Intern Med 2007; 146:631-9.

9. Catanoso MG, Macchioni P, Boiardi L, et al. Treatment of refractory polymyalgia rheumatica with etanercept: an open pilot study. Arthritis Rheum 2007;57:1514-9.

10. Caporali R, Cimmino MA, Ferraccioli G, et al. Prednisone plus methotrexate for polymyalgia rheumatica: a randomized, double-blind, placebo-controlled trial. Ann Intern Med 2004;141:493-500.

11. Leeb BF, Rintelen B, Sautner J, et al. The polymyalgia rheumatica activity score in daily use: proposal for a definition of remission. Arthritis Rheum 2007:57:810-5.

12. Binard A, de Bandt M, Berthelot JM, et al. Performance of the polymyalgia rheumatica activity score for diagnosing disease flares. Arthritis Rheum 2008;59:263-9.

13. Leeb BF, Bird HA, Nesher G, et al. EULAR response criteria for polymyalgia rheumatica: results of an initiative of the European Collaborating Polymyalgia Rheumatica Group (subcommittee of ESCISIT). Ann Rheum Dis 2003;62:1189-94.

14. Leeb BF, Bird HA. A disease activity score for polymyalgia rheumatica. Ann Rheum Dis 2004;63:1279-83.

15. Binard A, Lefebvre B, De Bandt $\mathrm{M}$, et al. Validity of the polymyalgia rheumatica activity score in primary care practice. Ann Rheum Dis 2009;68:541-5

16. Binard A, De Bandt M, Berthelot JM, et al. Usefulness of the disease activity scores for polymyalgia rheumatica for predicting glucocorticoid dose changes: a study of 243 scenarios. Arthritis Rheum 2007; 57:481-6.

17. Dasgupta B, Salvarani C, Schirmer M, et al. Developing classification criteria for polymyalgia rheumatica: comparison of views from an expert panel and wider survey. J Rheumato/ 2008:35:270-7.

18. Salvarani C, Cantini F, Boiardi L, et al. Polymyalgia rheumatica and giant-cell arteritis. N Engl J Med 2002;347:261-71.

19. Zhang Y, Jordan JM. Epidemiology of osteoarthritis. Rheum Dis Clin North Am 2008:34:515-29.

20. Machold KP, Köller MD, Pflugbeil S, et al. The public neglect of rheumatic diseases: insights from analyses of attendees in a musculoskeletal disease awareness activity. Ann Rheum Dis 2007;66:697-9.

21. Blockmans D, De Ceuninck L, Vanderschueren S, et al. Repetitive 18-fluorodeoxyglucose positron emission tomography in isolated polymyalgia rheumatica: a prospective study in 35 patients. Rheumatology (Oxford) 2007:46:672-7.

22. Hachulla E, Saile R, Parra HJ, et al. Serum amyloid A concentrations in giant-cell arteritis and polymyalgia rheumatica: a useful test in the management of the disease. Clin Exp Rheumatol 1991;9:157-63.

23. Narváez J, Nolla-Solé JM, Clavaguera MT, et al. Longterm therapy in polymyalgia rheumatica: effect of coexistent temporal arteritis. J Rheumatol 1999;26:1945-52

24. Pego-Reigosa JM, Rodriguez-Rodriguez M, Hurtado-Hernandez Z, et al. Calcium pyrophosphate deposition disease mimicking polymyalgia rheumatica: a prospective followup study of predictive factors for this condition in patients presenting with polymyalgia symptoms. Arthritis Rheum 2005;53:931-8.

25. Salvarani C, Cantini F, Macchioni P, et al. Distal musculoskeletal manifestations in polymyalgia rheumatica: a prospective followup study. Arthritis Rheum 1998:41:1221-6

26. Salvarani C, Cantini F, Niccoli L, et al. Acute-phase reactants and the risk of relapse/ recurrence in polymyalgia rheumatica: a prospective followup study. Arthritis Rheum 2005:53:33-8.

27. Cantini F, Salvarani C, Olivieri I, et al. Erythrocyte sedimentation rate and C-reactive protein in the evaluation of disease activity and severity in polymyalgia rheumatica: a prospective follow-up study. Semin Arthritis Rheum 2000;30:17-24.

28. Bengtsson BA, Malmvall BE. Prognosis of giant cell arteritis including temporal arteritis and polymyalgia rheumatica. A follow-up study on ninety patients treated with corticosteroids. Acta Med Scand 1981;209:337-45 
29. von Knorring J. Treatment and prognosis in polymyalgia rheumatica and temporal arteritis. A ten-year survey of 53 patients. Acta Med Scand 1979;205:429-35.

30. Behn AR, Perera T, Myles AB. Polymyalgia rheumatica and corticosteroids: how much for how long? Ann Rheum Dis 1983;42:374-8.

31. Kremers HM, Reinalda MS, Crowson CS, et al. Relapse in a population based cohort of patients with polymyalgia rheumatica. J Rheumatol 2005;32:65-73.

32. González-Gay MA, García-Porrúa C, Vázquez-Caruncho M, et al. The spectrum of polymyalgia rheumatica in northwestern Spain: incidence and analysis of variables associated with relapse in a 10 year study. J Rheumatol 1999;26:1326-32.

33. Bahlas S, Ramos-Remus C, Davis P. Clinical outcome of 149 patients with polymyalgia rheumatica and giant cell arteritis. J Rheumatol 1998;25:99-104.

34. Kremers HM, Reinalda MS, Crowson CS, et al. Use of physician services in a population-based cohort of patients with polymyalgia rheumatica over the course of their disease. Arthritis Rheum 2005;53:395-403.

35. Maradit Kremers H, Reinalda MS, Crowson CS, et al. Glucocorticoids and cardiovascular and cerebrovascular events in polymyalgia rheumatica. Arthritis Rheum 2007;57:279-86

36. Proven A, Gabriel SE, O'Fallon WM, et al. Polymyalgia rheumatica with low erythrocyte sedimentation rate at diagnosis. J Rheumatol 1999;26:1333-7.

37. Myklebust G, Gran JT. Prednisolone maintenance dose in relation to starting dose in the treatment of polymyalgia rheumatica and temporal arteritis. A prospective twoyear study in 273 patients. Scand J Rheumatol 2001;30:260-7.

38. Ayoub WT, Franklin CM, Torretti D. Polymyalgia rheumatica. Duration of therapy and long-term outcome. Am J Med 1985;79:309-15.

39. Murphy MK, Black NA, Lamping DL, et al. Consensus development methods, and their use in clinical guideline development. Health Technol Assess 1998;2:i-iv $1-88$.

40. Jones J, Hunter D. Consensus methods for medical and health services research. BMJ 1995;311:376-80.

41. Chuang TY, Hunder GG, Ilstrup DM, et al. Polymyalgia rheumatica: a 10-year epidemiologic and clinical study. Ann Intern Med 1982;97:672-80.

42. Dasgupta B, Dolan AL, Panayi GS, et al. An initially double-blind controlled 96 week trial of depot methylprednisolone against oral prednisolone in the treatment of polymyalgia rheumatica. Br J Rheumatol 1998;37:189-95.

43. Delecoeuillerie G, Joly P, Cohen de Lara A, et al. Polymyalgia rheumatica and temporal arteritis: a retrospective analysis of prognostic features and different corticosteroid regimens (11 year survey of 210 patients). Ann Rheum Dis 1988;47:733-9.

44. Feinberg HL, Sherman JD, Schrepferman CG, et al. The use of methotrexate in polymyalgia rheumatica. J Rheumatol 1996;23:1550-2.

45. Ferraccioli G, Salaffi F, De Vita S, et al. Methotrexate in polymyalgia rheumatica: preliminary results of an open, randomized study. J Rheumatol 1996;23:624-8.

46. Hutchings A, Hollywood J, Lamping DL, et al. Clinical outcomes, quality of life, and diagnostic uncertainty in the first year of polymyalgia rheumatica. Arthritis Rheum 2007:57:803-9.

47. Krogsgaard MR, Lund B, Johnsson B. A longterm prospective study of the equipotency between deflazacort and prednisolone in the treatment of patients with polymyalgia rheumatica. J Rheumatol 1995;22:1660-2.

48. Martinez-Taboada VM, Bartolome MJ, Fernandez-Gonzalez MD, et al. Homocysteine levels in polymyalgia rheumatica and giant cell arteritis: influence of corticosteroid therapy. Rheumatology (Oxford) 2003;42:1055-61.

49. Mertens JC, Willemsen G, Van Saase JL, et al. Polymyalgia rheumatica and temporal arteritis: a retrospective study of 111 patients. Clin Rheumatol 1995;14:650-5.

50. van der Veen MJ, Dinant HJ, van Booma-Frankfort C, et al. Can methotrexate be used as a steroid sparing agent in the treatment of polymyalgia rheumatica and giant cell arteritis? Ann Rheum Dis 1996;55:218-23.

51. Amoli MM, Shelley E, Mattey DL, et al. Intercellular adhesion molecule-1 gene polymorphisms in isolated polymyalgia rheumatica. J Rheumatol 2002;29:502-4.

52. Ceccato F, Roverano SG, Papasidero S, et al. Peripheral musculoskeletal manifestations in polymyalgia rheumatica. J Clin Rheumatol 2006;12:167-71.

53. Cimmino MA, Parodi M, Caporali R, et al. Is the course of steroidtreated polymyalgia rheumatica more severe in women? Ann N Y Acad Sci 2006;1069:315-21.

54. Cimmino MA, Salvarani C, Macchioni P, et al. Long-term follow-up of polymyalgia rheumatica patients treated with methotrexate and steroids. Clin Exp Rheumatol 2008:26:395-400.

55. Cutolo M, Straub RH, Foppiani L, et al. Adrenal gland hypofunction in active polymyalgia rheumatica. effect of glucocorticoid treatment on adrenal hormones and interleukin 6. J Rheumatol 2002;29:748-56.
56. González-Gay MA, Rodríguez-Valverde V, Blanco R, et al. Polymyalgia rheumatica without significantly increased erythrocyte sedimentation rate. A more benign syndrome. Arch Intern Med 1997:157:317-20.

57. Kyle V, Hazleman BL. The clinical and laboratory course of polymyalgia rheumatica/ giant cell arteritis after the first two months of treatment. Ann Rheum Dis 1993;52:847-50.

58. Lundberg I, Hedfors E. Restricted dose and duration of corticosteroid treatment in patients with polymyalgia rheumatica and temporal arteritis. J Rheumatol 1990;17:1340-5.

59. Pulsatelli L, Boiardi L, Pignotti E, et al. Serum interleukin-6 receptor in polymyalgia rheumatica: a potential marker of relapse/recurrence risk. Arthritis Rheum 2008:59:1147-54

60. Salvarani C, Boiardi L, Macchioni P, et al. Role of peripheral CD8 lymphocytes and soluble IL-2 receptor in predicting the duration of corticosteroid treatment in polymyalgia rheumatica and giant cell arteritis. Ann Rheum Dis 1995;54:640-4.

\section{APPENDIX}

Participating rheumatologists of the Delphi survey and members of the International Work Group for PMR and GCA:

Kenneth Calamia, Division of Rheumatology, Mayo Clinic College of Medicine, Jacksonville, FL, USA; Roberto Caporali, University of Pavia, IRCCS S Matteo Foundation, Pavia, Italy; Marco A. Cimmino, Department of Internal Medicine, University of Genova, Genova, Italy; Bhaskar Dasgupta, Department of Rheumatology, Southend University Hospital, Essex, United Kingdom; William Docken, Brigham Orthopedics and Arthritis Center, Chestnut Hill, MA, USA; Pierre Duhaut, Department of Internal Medicine, CHU Nord, Amiens, France; Miguel A Gonzalez-Gay, Division of Rheumatology, Hospital Xeral-Calde, Lugo, Spain; Roberto Gerli, Rheumatology Unit, Department of Clinical \& Experimental Medicine, University of Perugia, Perugia, Italy; Manfred Herold, Department of Internal Medicine I, Innsbruck Medical University, Innsbruck, Austria; Gery S. Hoffman, Department of Rheumatic and Immmunologic Diseases, Cleveland Clinic Lerner College of Medicine, Cleveland, OH, USA; Eugene Kissin, Boston University Medical Center, Boston, MA, USA; Peter Lamprecht, Department of Rheumatology, Vasculitis Center UKSH \& Clinical Center Bad Bramstedt, University of Lübeck, Lübeck, Germany; Burkhart Leeb, Lower Austrian Center for Rheumatology, Stockerau, Austria; Pierluigi Macchioni, Department of Rheumatology, Arcispedale Santa Maria Nouva, Reggio Emilia, Italy; Victor Martinez-Taboada, Division of Rheumatology, Hospital Marques de Valdecilla, Santander, Spain; Eric L. Matteson, Division of Rheumatology, Mayo Clinic, Rochester, MN, USA; Peter A Merkel, Division of Rheumatology, Boston University, Boston, MA, USA; Carlo M. Montecucco, University of Pavia, IRCCS S Matteo Foundation, Pavia, Italy; Gideon Nesher, Department of Internal Medicine, Shaare Zedek Medical Center, Jerusalem, Israel; Elisabeth Nordborg, Institute of Rheumatology, Huddinge University Hospital, Stockholm, Sweden; Colin Pease, Rheumatology and Rehabilitation Research Unit, University of Leeds, Leeds, UK; Carlo Salvarani, Department of Rheumatology, Arcispedale S. Maria Nuova, Reggio Emilia, Italy; Michael Schirmer, Department of Internal Medicine I, Innsbruck Medical University, Innsbruck, Austria; Wolfgang Schmidt, Department of Rheumatology, Berlin-Buch, University of Berlin, Berlin, Germany; Roberto Spierra, Beth Israel Medical Center, New York, NY, USA; Annette Wagner, Department of Rheumatology, University of Hannover, Hannover, Germany. 